\title{
1. Introduction to Leadership and Charisma
}

\section{POINT OF DEPARTURE}

In the TV series, The Crown, about the British royal family, a dialogue is presented between the young Queen Elizabeth, who is facing her coronation as Queen, and her husband, the Duke of Edinburgh. The Queen, on the advice of the royal court veterans, wants to perform the ceremony as it has always been conducted - as a "sacred" ceremony that takes place away from the public eye in exactly the same way, with the same rituals that have always existed like other religious rituals.

Her husband suggests changing the ceremony, in the spirit of "the changing times". He suggests broadcasting it on television to make it more popular, more transparent, and less attached to the historic protocol. The main difference between the two approaches focuses on the following arguments:

The Duke of Edinburgh: People want to see their heroes as flesh and blood people - "up close", with all their weaknesses.

The Queen: People want to see us being exalted, above the people. They do not want to perceive us as ordinary people because this detracts from the "comforting effect" that royalty has on people.

This dialogue reflects various assumptions about the attitude of followers toward leaders. Do followers have a tendency to romanticize leaders - to see them as a desired story? ${ }^{1}$

The book deals with this riddle. It examines the roots at the base of leadership as a phenomenon. Particularly, it focuses on people's strong attraction to leaders, as a result of their "charismatic nature". Such an examination begins with the fact that leadership is not an exclusive human phenomenon; leadership also exists among many animals. Animals whose lives are conducted in flocks also have a social 
hierarchy; yet, as is discussed in the book, despite common foundations, human beings have unique manifestations regarding the phenomenon of leadership.

Charisma is, first and foremost, associated with strong emotions. It is sometimes likened to falling in love, ${ }^{2}$ and as with falling in love, it has a subjective element. It can exist in the eyes of followers at some point and disappear later. If charisma is claimed to be a phenomenon "in the eye of the beholder", the obvious question is: Why hasn't research focused more on followers - specifically, on the sources and purposes of their longing for and attraction to leaders? That is, on the patterns of the followers' construction of leadership images?

Such an observation requires a theoretical, out-of-the-box approach an effort that is always extremely difficult. As is well known, the most natural tendency is to follow an established path - certainly this is the case in research that typically relies on previous studies, similar to relying on precedents in the legal world.

The point of departure for the presented discussion is that leaders are only part of the leadership phenomenon, which needs to be examined along with two additional components: followers and context. A metaphor that has greatly influenced us is the one that likens leadership to fire. Fire is ignited by the leader, who is the spark. However, it ignites various combustible substances that differ in the degree of their combustion potential. Some followers are more "flammable" than others. The combustion itself - the duration and height of its flames - is fed by oxygen, which feeds the fire - in this case, the environment and the circumstances.

So, what is the cause and what is the outcome of this fire/combustion process? Is it an interaction? If so, what is its nature? These are complex questions which the book discusses. Moreover, there is a genuine need to clarify issues given the claim that most comparative research on human behavior is mainly focused on countries referred to as WEIRD societies (Western, Educated, Rich and Democratic), which represent 80 percent of the research and only 12 percent of the world population. ${ }^{3}$ The meaning of this disproportion is, of course, clear with regard to the generalization of findings. But beyond that, it is possible that in general, the reference to certain phenomena is cultural, and therefore any comparative bar is problematic in the first place. A book that dealt with cultural influences on the perception of visual stimuli showed that people from different cultures perceived visual stimuli, or parts of them, in a way that derived from their culture. ${ }^{4}$ If this is the case with visual images (which are supposed 
to be objective and universal stimuli), it goes without saying that there is a problem with studies of more complex phenomena.

Here is another illustration of the meanings of partial or biased sampling in the context of medical care. A recent television article presented a case in which symptoms such as pressure in the chest area, left arm pain, and difficulty breathing - "typical signs" of a heart attack, which usually cause people to rush to the emergency room - are not necessarily relevant signs of a heart attack in women.

The TV article presented evidence of women who thought they had heartburn, came to the emergency room and received heartburn medication, but had actually experienced a heart attack.

How does such a diagnostic error occur? The explanation provided by medical experts is that the vast majority of subjects in medical research in the field of cardiology are men. Thus, the ever-improving treatment methods following technological advancements (such as MRI, for example), and the development of sophisticated statistical software, which can achieve incredible levels of accuracy and measurement, may be biased and even erroneous, only because the point of origin is the over-representation of men. If this is the case with regard to specific visual stimuli or diagnostic medical data, obviously, it is even more complex when it comes to psycho-social phenomena. Charisma is just one such phenomenon, and probably one of the most elusive. ${ }^{5}$

Indeed, a bird's eye view of the history of leadership research ${ }^{6}$ raises the well-known association of the Indian parable of the elephant and the group of blind men, in which each blind man touches and recognizes a single part of the elephant's body - trunk, foot, and so on - each "sees" something different, and none succeeds in identifying the animal as an elephant. The danger of reduction - of seeing trees while ignoring or failing to even look at the whole forest - can lead to conceptual biases and inaccuracies.

Moreover, many who watch movies about Hitler or Jim Jones - the leader of a cult that convinced 911 of its members to commit suicide - wonder how these men could have had such a tremendous amount of charisma. To many, they even look ridiculous. Such perplexity accompanies us in many observations of leaders. Even in daily conversations about politicians, there is often a debate about the charisma of leaders: whereas some perceive a particular leader as charismatic, others simply cannot see the attraction.

These examples and questions make it clear, at the most simplistic intuitive level (at this point), that charisma is first and foremost a great 
influence on people. Singers, actors, or lecturers can also be charismatic in the sense described.

The book focuses on charismatic leadership - a phenomenon which, in our opinion, is not only psychological and anthropological, but has evolutionary foundations and a role in the intergenerational development of groups. Moreover, in recognizing charismatic leaders in human history, such as Nelson Mandela or Benito Mussolini, it cannot be said that charisma is necessarily a "good thing". It can promote non-violence (Mahatma Gandhi), but it can just as easily promote destruction and devastation (Adolf Hitler). And as with infatuation, charisma is not necessarily stable; it can exist for a period of time and later disappear. ${ }^{7}$ If charisma is, as we claim, a phenomenon which is "in the eye of the beholder", then why does the research literature not deal more with the observers - the followers - the patterns of their emotions and unconscious echoing to figures perceived as charismatic?

This book attempts to answer this question and others: Why are we attracted to leaders? What are the universal and cultural components which underlie our "falling in love" with certain leaders? Why are we attracted to different types of leaders? Why do we perceive certain leaders as charismatic? Why are some leaders more charismatic in our eyes than others? Why do those leaders who are perceived as charismatic in one period, stop being perceived as such in another period? Or vice versa: those who are not perceived as charismatic leaders become more charismatic during other periods. Why do some leaders become "forever charismatic" beyond time and place, while others who were extremely charismatic in their time fall into the abyss of oblivion and are all but forgotten?

The book's uniqueness lies in the fact that it perceives leadership as an inherent ingredient rooted in the "evolutionary software" of humankind. This does not mean that the leadership of a lioness leading a band is like the leadership of a state leader, team leader, or corporation leader. There are common elements; however, it is clear that there are also differences explained by the unique development of human beings.

In this sense, this book is not "another book on leadership", but rather an observation of a phenomenon that is essentially too complex to be understood through a single disciplinary lens. The book presents a perspective that integrates evolutionary, psychological, sociological, and anthropological angles, all of which shed light (also through historical observation) on a phenomenon that exists in every society, large and small. 
The beginning of the journey is in evolutionary observation. From there, it is possible to follow developments that clarify the components underlying human leadership. The analysis clarifies what, in the phenomenon of leadership, can be generalized beyond all cultures and which elements in this phenomenon are culturally bound.

\section{THE CONCEPTUAL FRAMEWORK}

Leadership is one of the most discussed and researched phenomena. A review of the literature on leadership research indicates the clear dominance of American literature on leadership. ${ }^{8}$ This literature often presents leaders as cultural heroes: remarkable independent individuals, entrepreneurs, revolutionary pioneers, courageous figures, and so on. These are not random descriptions. They typify American culture, which has glorified individualism from an early age. ${ }^{9}$

In one study, social psychologists Hazel Markus and Elissa Wurf ${ }^{10}$ describe the same situation - that of a mother feeding her small child - in the United States and Japan. To her son who refuses to eat, the American mother says things like, "Don't you want to be a famous basketball player?"; and "How will you be strong enough if you don't eat all your food?" In the same situation, the Japanese mother tells her small son about the many people who prepared the food: the cowherd who milked the cow, the person who turned the milk into cheese, the people who packed the cheese, the driver who drove the cheese to stores ... Finally, she asks: "Do you not respect the efforts of all these people who were busy preparing food for you?" And so, from early childhood, different norms, such as individualism and collectivism, are internalized. Such norms are also later expressed in reference to leaders.

Literature about American organizations depicts the leadership of managers like Jack Welch (CEO of General Electric) as icons presented in the business press and US business schools as role models. On the other hand, successful Japanese companies, like Toyota, emphasize the "method" rather than the leaders. ${ }^{11}$ Hence, cultural differences, as the Dutch organizational researcher Geert Hofstede showed, ${ }^{12}$ can paint the images of leaders in different colors. This, of course, casts doubt on the ability to generalize arguments about leadership.

As noted, such insights have led us to search for patterns whose understanding can contribute to the distinction between the universal and the local-cultural aspects in the discussion of leadership. To do this, we start from the beginning - the evolutionary observation that makes 
it possible to examine what can be generalized beyond the different cultures, and what requires understanding of cultural and situational contexts. Important insights for this analysis include those described in the subsections below.

\section{Discussion of Leadership Is Essentially a Discussion of the Phenomenon of Followership}

The literature has dealt extensively with leaders. Hundreds of biographies have been written about leaders such as Washington, Lincoln, Mahatma Gandhi, Ben-Gurion, and Ata Turk, among others - generators of national revivals or dramatic upheavals, who have become both national mythologies and symbols of collective identity. Such stories are so popular that it has become a genre of written history. For example, James McGregor Burns - whose monumental book, Leadership, ${ }^{13}$ is considered one of the most influential books in the field of leadership studies - was actually referred to as a "presidential scholar", as he specialized in writing biographies of US presidents (especially the Roosevelts). The fact that biography is perceived as an inferior genre of historical research, but the most popular when it comes to sales, ${ }^{14}$ indicates that people are biased in favor of personal stories.

American psychologist, Jerome Bruner, noticed this love of stories in humans. ${ }^{15}$ This tendency is visible and direct among children, but in fact no less so among the "older children" - the adults. The fact is that most of us eagerly read stories about people and their lives in novels, gossip magazines, and weekly supplements; and watch TV shows that are personal and intimate with great interest. The story of Albert Einstein's life, for example, interests most people more than his claims about cosmology.

Within this propensity for life stories, leaders' stories are probably more fascinating than those of most other known people while stories about leaders who were "scoundrels" are probably even more fascinating (similar perhaps to the attraction to crime drama heroes?). The books written about Hitler, for instance, are more numerous than those written about most of the leaders in human history.

The esteemed British historian, Ian Kershaw, who wrote, according to many, the most comprehensive biography of Hitler, ${ }^{16}$ wrote in the introduction to the book about the different approaches to historical research and his dilemma in writing - which ranged from the structural approach to focusing on the man himself. Kershaw claimed that the concept "charismatic leadership", as discussed by Max Weber, helped 
him to integrate the different approaches. "If I have found one concept more than any other which has helped me find a way to bind together the otherwise contradictory approaches through biography and the writing of social history, it is Max Weber's notion of 'charismatic leadership'."17 Charisma, as deployed by Weber, is "a notion which looks to explanations of this extraordinary form of political domination primarily in the perceivers of 'charisma', that is, in the society rather than, in the first instance, in the personality of the object of their adulation". ${ }^{18}$ That is, those who seek explanations for the extraordinary influence of charismatic leaders, argues Kershaw, should seek it in society and not necessarily in the personality who is the object of admiration.

There is another aspect that Kershaw raised in his descriptive reports, but did not sufficiently relate to its full psychological implications: The influence of followers on the self-expectations and self-image of the leader. At the beginning of his political career, Hitler saw himself, as he wrote in Mein Kampf, as a "drummer" - calling the masses to the banner of the "national movement". At that time, he still did not see himself as the future leader of Germany, but rather as one who paves the way for the great leader whose time might come in many years. As he told his associates, "I am nothing more than a drummer and rallier (Trommler and Sammler)." 19

He explains he was not the leader and statesman who would "save the Fatherland that was sinking into chaos", but only "the agitator who understood how to rally (sammeln) the masses". He added that he was not "the architect who clearly pictured in his own eyes the plan and design of the new building and with calm sureness and creativity was able to lay one stone on the other. He needed the greater one behind him, on whose command he could lean." ${ }^{20}$

All that, however, changed over time. The mob's admiration for him as a speaker at the Munich mass rallies changed his self-image and self-expectations. He began to believe he was, indeed, that great leader the one who would save and glorify Germany. As the social psychologist and leadership researcher, Boas Shamir, noted, there is evidence here of a process that requires a change in focus - from the leader figure and his needs toward understanding the needs of the followers. ${ }^{21}$

Leadership literature has mainly dealt with one direction of influence - the leader's influence on his/her followers. This, however, is a partial and perhaps even distorted perspective. Leaders are greatly influenced by the dynamics and expectations of their followers. In some cases, this is even the key to understanding their impact. 


\section{Followers Have Inherent Biases in Processing Information Concerning Leaders}

The most common bias followers have in their attitude toward leaders is the tendency to give more weight to people than to processes - a bias known as "fundamental attribution error" in the field of social psychology. ${ }^{22}$ For example, in a well-known study, ${ }^{23}$ people were asked to choose one out of four different reasons to explain the success of events. All reasons were equally probable. However, most people chose leadership as the explanation for the success. People, for example, almost exclusively attributed the upheaval that took place in the Soviet Union to Gorbachev. Much less weight was given to economic or social processes (e.g., the long decline of the Soviet economy, which showed that the "system" did not work).

Such biases are also conspicuously evident in election campaigns in the Western world. Most people do not analyze social, economic, or geopolitical processes when it comes to voting in elections. The majority does not even read the parties' platforms. The real choice, in fact, is about the leader who heads the party - a clear manifestation of the fundamental attribution error. This bias intensifies the more distant the leader figure is. The less the leader is subjected to direct observation, the greater the subjective elements in constructing the leader's image. This is part of the general patterns found in social psychology studies that deal with "psychological distance". ${ }^{24}$ For example, a study conducted among American students presented them with a possible occurrence that could happen in the near/distant future: "In a few days/years, the university will be prepared to increase the quota of minorities admitted to the university." Students were then given a list of statements (e.g., preparation of potential candidate lists) expressing an ideological-moral reference (e.g., reducing inequality in society, justice). It was found that ideological-moral references were more common in the context of the distant future. The closer the situation was in time, the less the ideologi$\mathrm{cal} /$ moral references were mentioned. ${ }^{25}$

The principle according to which construal of objects, events, and people is more abstract the more distant they are is particularly conspicuous when it comes to images of leaders. Boas Shamir ${ }^{26}$ demonstrated some important aspects of this argument. In his study, 320 students from The Hebrew University of Jerusalem were interviewed. They were asked to describe a leader who had no direct contact with them - a "distant leader" (81 percent of the distant leaders were political leaders), 
and to describe a leader with whom the interviewee had direct contact and acquaintance - a "close leader" ( 28 percent of them were teachers, 26 percent were commanders whom they knew personally from the army, and 24 percent were friends). Comparing different characteristics between the images attributed to distant and close leaders, it was found that there was a greater wealth of characterizations regarding close leaders, and these characteristics were more specific and more behavioral (e.g., expressions of expertise, personal example) compared to those attributed to distant leaders, which were described in more abstract and simplified terms (e.g., social courage and ideological orientations). The distant leaders were sometimes described as "larger than life". Indeed, some scholars have argued that distant leaders are more prone "to processes of romanticization and mythologization". ${ }^{27}$ Abraham Lincoln - the most revered president in the history of United States - became an icon of charisma only decades after his death. He is a clear manifestation of a mythological story. Had there not been some leading newspaper editors in the early twentieth century, Lincoln would probably have sunk into the abysses of oblivion. ${ }^{28}$ Dead Lincoln is undoubtedly more charismatic than living Lincoln.

In terms of the psychology of followers, this description points to two phenomena that have been extensively discussed in psychology: (1) projection and (2) attribution. Although the two terms differ, they both point to the same direction of human ability in the context of leadership: the ability to construct characteristics of "greatness" (power, wisdom, etc.) and relate them to certain entities and figures. This ability, which is probably unique to humans, generates a sense of confidence and calmness, and even reduces oppressive emotions such as guilt feelings. ${ }^{29}$ From this point of view, God for example, is the ultimate leader. To millions of believers, he can be exactly what his followers want him to be. The figures who are considered close to him (Muhammad, Jesus, Moses) are known as the most charismatic leaders in human history. ${ }^{30}$

Thus, projection and attribution are central psychological mechanisms that allow people to "anoint" leaders. This ability is related to primary and universal needs - such as security, which seems prominent in situations of crisis, uncertainty, and change; and symbolic needs - related to meaning, and to personal and group identity.

Appointing Moshe Dayan, the most famous Israeli General in the 1960s, as Minister of Defense on the eve of the Six Day War, under public pressure (contrary to the preference of then-Prime Minister Levy Eshkol), is an example of two previously discussed processes: (1) the 
search for a "great figure" that provides a "response" to collective existential anxieties (Dayan enjoyed the aura of a successful chief of staff); and (2) symbolic and culturally bound processes: the almost unconditional trust given to leaders from military backgrounds in Israeli society (part of the ethos of a nation that fights for its existence).

Indeed, leaders have a symbolic power, which explains followers' attraction to different figures in various cultural groups. In an experiment we have been conducting for many years among students and in training workshops on leadership, we begin with an "opening exercise": we ask participants to name leaders. It turns out that most of the chosen leaders are mentioned by all of the groups. For example, Churchill, Mahatma Gandhi, John F. Kennedy, Abraham Lincoln, Ata Turk, Hitler, Nelson Mandela, Ben Gurion, and Yitzhak Rabin always appear on every list. Therefore, it can be said that these names are a representative sample the personification of leadership as a phenomenon.

After writing the names on the board, we try to find the "organizing principles" at the basis of the phenomenon that has been reflected by the class. What quickly becomes clear is that it is difficult to find common patterns and behavioral rules. Some leaders are characterized by their outstanding rhetorical ability (e.g., Hitler), while others are stutterers (e.g., Yitzhak Rabin). Some are good looking (e.g., Kennedy), while others are not considered to be particularly attractive (e.g., Gandhi). In short, no single visible characteristic can be pointed out as a "threshold condition" or prerequisite for becoming a leader. However, this discussion changes when analyzed from the perspective of the followers' needs. Then, the basic contours of the phenomenon become clear: the need for security and direction, and the centrality of the feeling that "there is someone to trust". These emotions commonly come to the fore, and will be dealt with more extensively in the following chapters.

Interestingly, when presenting this request to Orthodox Jews who grew up within what can be described metaphorically as a "cultural island", detached from the dominant culture, a different pattern emerged. The leaders indicated are rabbis (e.g., Rabbi Kook, Rabbi Solovitchik, Rabbi Ovadia Yosef) and other religious, folkloristic figures such as the Baal Shem Tov and the Rabbi of Lubavitz).

These examples illustrate three principles that will be expanded further. (a) The phenomenon of leadership is also culturally bound and associated with the symbolic world of the group. (b) Learning about leadership is greatly influenced by the figures we are exposed to in our socialization processes. (c) Belief in the leader as a symbol empowers 
the group. These principles have many implications for "leadership consumption" processes, which are part of a broader phenomenon of the intergenerational transfer of symbols. Anyone who has visited a Chabad (a distinct group of Orthodox religious Jews) synagogue can see these principles in action - in the constant storytelling and wonder surrounding the figure of the Lubavitcher Rebbe. This is basically a process of romanticization and mythification of the leader. Such processes can be found in many cultures and are part of an understanding of the phenomenon of leadership in general, and charismatic leaders in particular.

It seems that one basic process becomes clear: the more distant the leader is from the followers, the more $\mathrm{s} / \mathrm{he}$ is the manifestation of the followers' projections and attributions. The leader is presumably a story, sometimes mythological, that serves the followers' different needs. Such aspects of "constructing leaders" have been partially studied in the leadership literature. They were mainly presented in writings in which leadership was analyzed using psychodynamic theories relating essentially to unconscious processes, or in studies grounded in social-psychological theories dealing with various social information processes. The result is hundreds of studies that do not provide a wide enough view into the phenomenon of leadership as a whole.

After much deliberation, we thought that in order to reduce "researchers' biases", "school-of-thought biases", or "cultural biases" it might be insightful to return to the fundamentals that exist in nature. That is, to rely on the same reasoning underlying many developmental studies which assumes, for example, that toddlers have not yet been influenced by social or political socialization. In short, we focused on defining the initial and authentic elements in the phenomenon of leadership. However, we argue that understanding these foundations is not the "whole story", but it helps to understand the origins of differential attitudes toward leaders which are ostensibly only "cultural".

\section{The Phenomenon of Leadership Is Primarily Emotional}

Another insight that comes from turning the spotlight on the followers is the centrality of emotions in the discussion of leadership. Ignoring or reducing the reference to the emotional component in early studies in social sciences in general, and in the research on leadership in particular, is probably due to the centrality and prestige of researchers and research in the natural sciences. It is well known that the founding researchers in psychology aspired to adopt the way of thinking and research methods 
that characterizes the natural sciences. For example, researchers such as Fredrick Skinner and Kurt Lewin were clearly considered more "scientific" as they conducted lab experiments and dealt with measurable variables. ${ }^{31}$

The streams in psychology that clearly dealt with emotions, such as the psychoanalytic school of thought, were controversial in the academic world. Proponents of Freud and his successors also saw the psychodynamic arguments as "thoughts" and the practices derived from them as "art", rather than science. Indeed, for many years, paradoxically, psychology - the discipline that is assumed to deal with human nature - has reduced research interest in aspects that are not only typical of human beings - in some cases, they are unique to them. "Compassion", "love", "hate", "friendship", "jealousy", "revenge" - the very core issues of which life is composed - were not at the forefront of research. People pondered and discussed these aspects through novels, films, and plays.

True, there have been developments in this regard in recent years, but this may be due to the maturation of technologies that advance neuropsychological research capabilities. Evidence is growing on correlates of empathy in the brain; studies are being conducted on the effect of oxytocin on social emotions, and so on. This is a trend that has hope and perhaps promise for understanding worlds that were not at the forefront of research. Still, the findings are essentially correlational, while the big integrative picture remains largely enigmatic.

One way or another, there is undoubtedly a greater degree of legitimacy today for engaging in a field called "emotions research". A number of today's universities have research institutes that focus on the study of emotions. Interdisciplinary collaborations in the study of emotions exist, and even issues like interstate or intergroup conflicts are being explored from theoretical perspectives that deal with emotion regulation. ${ }^{32}$

Associating emotion with evolutionary sources was discussed impressively in a theoretical paper published about 40 years ago by Stanford University's social psychologist, Robert Zajonc. ${ }^{33}$ This paper argued that, in many cases, emotion "jumps" prior to processing information in the brain.

One of the most helpful and common distinctions in recent years is the distinction between system $1-$ a decision-making system that is fast, emotional, and "uncalculated" (falling in love); and system 2 -which is responsible for calculated decisions (buying a car or investing in the stock market). ${ }^{34}$ We argue that emotions are central in choosing leaders 
and following them. This is especially conspicuous during election campaigns. We will dedicate an analysis to this specific situation.

To sum up the general claim in broad terms, it can be said that looking at leadership and followership from the perspective of "backward inquiry" ultimately leads to the foundations that characterized the beginning of human evolution. Some of these factors are universal and common to all humankind (e.g., fear of snakes ${ }^{35}$ ), while others are group-level factors that have evolved into intercultural differences. ${ }^{36}$ In the book, these links are discussed at length, within the context of leadership and followership.

The general argument is that the initial attraction to leaders is universal. Those individuals experienced by others as most able to address the group's fundamental, existential needs are perceived as more attractive. Those who transmit particularly prominent signals in this context will be experienced by others as more charismatic - that is, they will have a particularly strong impact. From where do such signals derive their appeal? What is behind the influence of people we experience as charismatic? What is at the core of the electrifying impact of, say, Martin Luther King's "I Have a Dream" speech? What caused Rev. Jim Jones's followers to commit suicide and even kill their children? We should note that such phenomena are not uncommon in our history, as is clearly seen in literature, films, plays, and other art forms. And yet, it is very difficult to explain this impact. ${ }^{37}$

Throughout the book, we will try to show that the gap between the prevalence of the experience of a strong influence, and the ability to explain it in research, is not accidental. We will present the possibility that it is difficult to explain such an effect, without exceeding the level of analysis we usually use to explain the conventional rules existing between human beings in daily life. This may be the reason for the Greek origin of the word charisma (God's gift) and our "magical" attributions toward it. It is no coincidence that this phenomenon is considered "irrational", surprising, and contradictory to our beliefs about free will. This happens because it is a phenomenon that belongs to different rules, which are beyond observed daily conduct. These rules are associated with aspects that serve humans, but humans do not define them. It is based on the foundations of the human race as a whole, rather than on interpersonal differences. This argument may contribute to a more modest and careful approach to everything that is described in the leadership literature in terms of "unusual greatness".

The difficulty in a discussion on prominent universal signals associated with evolutionary claims stems from the fact that charismatic leaders 
do not have objective and identical contours that are always generalizable beyond different collectives (such as height). Charisma is also related to symbolic differences between groups, such as differences between national cultures. Evolutionary observation can also shed light on the source of these differences and how they came about.

As is well known, the human individual was neither the strongest nor the fastest creature in the struggle for survival. His adaptive advantages stemmed largely from his ability to work in a group. Homo sapiens developed a culture (language, norms, practices) that made the choice of leaders and the attachment to them more complex, compared to the initial attraction to leaders based on the primary adaptive needs. However, looking at the cultural development of different groups points to an evolutionary logic illuminating the formation of different images of charisma. Although Gandhi is an Indian leader, the underlying explanation for his development into a symbol - a charismatic leader - has a rationale that is related to characteristics of Hindu culture. This argument is relevant to leaders in other cultures as well. The symbols of different collectives (including images of leadership) are distinct and unique to different collectives. However, the need for symbols is universal. Its foundations are anchored in the evolution of the group. The book describes these processes and how they are related to leadership and followership.

\section{THE BOOK'S STRUCTURE}

Chapter 2, "Evolution and sensitivity to signals", presents the theoretical point of departure, anchored in an evolutionary paradigm. When the word "evolution" is mentioned, the immediate associations that arise are the thoughts and theories of Charles Darwin. However, beyond his observations about biological evolution, Darwin's way of thinking has contributed greatly to theoretical developments in various fields - from the social sciences to disciplines such as computer science.

Darwin's ingenious observations focused the world's attention on living organisms' ongoing adaptation processes in relation to the environment. This view requires the ability to relate to different layers that were not addressed at the same level of conceptual and empirical analysis. For example, the research that developed following Darwin's ideas emphasized biological adaptation in different environments, including weather, geographical, and geological aspects. However, Darwin's ideas were not fully utilized in this context. 
In his reference to the environment in On the Origin of Species, Darwin introduced the idea of "spaces in the natural economy", now known as "niches", that are different in terms of abundance and availability of resources that create different adaptation conditions. The well-known concept of "variation" is therefore also relevant at the level of intergroup differences and has been attributed with multiple ways of explaining intercultural differences between human groups that developed in various adaptive niches. ${ }^{38}$ Such observations can, of course, shed light on the different preferences and sensitivities of different groups (such as why some societies are more collectivistic, while others are more individualistic) ${ }^{39}$

Furthermore, in many cases, the transfer of adaptive knowledge is not detailed enough beyond biological expression. For example, in an experiment in which cat hair was left among mice that had never seen a cat, they responded with a panic-and-escape response. This was not their reaction when dog hair was left near them. Thus, it would seem clear that some knowledge is passed down from generation to generation. ${ }^{40}$

Evolutionary observation can expand our understanding of intergenerational learning, which is more complex than the initial evolutionary ideas. Emotions, norms, and cultural knowledge can also be transferred through intergenerational processes. Such ideas can be traced, for example, in Jung's ideas on cultural archetypes or in Max Weber's theory on religious values passed down from generation to generation - values that affect attitudes toward work and lifestyles. ${ }^{41}$ This idea is also echoed in works on emotions passed down from generation to generation as a result of collective trauma, such as among survivors of the European or Armenian Holocaust. ${ }^{42}$ These examples suggest that "biological" hardware is not the entire story. Apparently, emotional and cultural aspects also have an impact on intergenerational learning. ${ }^{43}$ This point is central in trying to explain social phenomena such as leadership.

The literature that has developed around these issues is enlightening in that it shows cultural evolution among various collectives; however, it is lacking at the micro level. That is, it does not focus on the following questions: How does this learning occur? How do cultural norms and practices actually pass from generation to generation? Attempts to explore and conceptualize these intergenerational learning processes have evolved greatly over the past two decades ${ }^{44}$ and have significantly contributed to the development of the arguments presented in the book regarding the ways in which charismatic leaders influence followers. ${ }^{45}$

Leaders are described by many scholars in terms of identity, loyalty, and group patriotism. There is a general romanticization of leaders in 
every collective. However, going back to the beginning of the development of Homo sapiens, prior to the formation of language, indicates that leadership began as the simplest coordination mechanism of group activity, ${ }^{46}$ which is basically the foundation of any organization. As the organizational researcher, Henry Mintzberg, pointed out in his work, organizations can be classified according to their coordination mechanisms. In small organizations, the manager-leader can clearly be seen as fulfilling a key coordinating function. ${ }^{47}$

Concepts in contemporary literature about leadership such as "direction", "alignment", and "commitment" 48 are expressions concerning a means by which to improve this primary and universal function. In other words, the development of the language and the symbolic abilities of Homo sapiens enabled the existence of more abstract, more complex channels of communication. However, at their core, they serve an ancient purpose - group coordination.

This claim will be further elaborated in the discussion regarding the universal foundations of leadership as a catalyst for two adaptive axes: (1) a horizontal axis of coordination and synchronization that contributes to group cooperation through coping with present adaptive challenges; and (2) a vertical axis comprised of knowledge and the group's symbols transferred over generations.

These universal aspects are sometimes blurred because cultural differences are reflected in different images of charismatic leaders. ${ }^{49}$ For example, the American researchers, Gerstner and Day, compared leadership perceptions among student population in eight countries. They presented the subjects with 59 leadership characteristics and found that the degree of agreement about them was so small that they could not indicate leadership "core images" around which there was clear agreement. Moreover, none of the top five leadership characteristics found in the US sample was ranked as the top five in the other samples. ${ }^{50}$

In an interview, an Israeli researcher, who grew up in Turkey and specializes in Turkish culture, characterized the cultural aspect of the Turks' attitude toward their highly controversial (in the West) leader, Erdogan. In answer to the interviewer's question: "How do the Turks come to terms with the thousand-room palace Erdogan built, with his private plane, and his masses of servants?", the reply was: "Turks are not Israelis. Think of the Ottoman Empire - the Turks are used to sultans living in palaces. Ataturk also lived in a palace in Istanbul. For the average Turk, it is natural for a ruler to live in a palace; it is not considered a sign of 
corruption. On the contrary, it shows that the country is glorious, that it has power." 51

However, these differences regarding the sensitivity of different collectives to different symbols should not obscure the common principle that groups need shared, unifying symbols - both for their cohesion and resilience in the present (the horizontal axis) and as a basis for preserving this resilience in the future (the vertical axis). As will be elaborated, leaders serve this universal need by being both agents and "manufacturers" of unifying symbols.

This discussion also illustrates a central idea discussed in the book at length: the idea of signals. The book's focus is not on leaders' personality characteristics, but on which signals experienced by followers are perceived as relevant enough to "anoint" some individuals (more than others) for leadership positions. There are several prominent signals that particularly help followers identify leaders. Some of the signals, as mentioned, are universal and are clearly and closely related to basic existential needs, while others are acquired during cultural learning processes. Understanding the dynamics of these signals illuminates the combination of the universal and cultural elements underlying the influence we call "charisma". This is a central argument in the book, exemplified through various studies and examples, some of which are well known in human history.

Chapter 3, "The attraction to leaders", focuses and expands the discussion on the signals that are experienced by the followers as "signs of leadership". The chapter presents two types of signals: the first signal concerns the primary needs in adaptive processes. These signals are common among all animals who perceive a certain individual animal as being more capable than others of helping them face environmental threats. At the more primitive levels, such signals reflect physical strength. At the more complex levels, these signals are more sophisticated, but they point to the same need - a response to threats and challenges.

Through the presentation of studies and historical examples, the chapter describes the leadership signals that are most prominent in two situations: in times of crisis and during election campaigns. Our instinctive sensitivity to such signals (despite all attempts at denial) illustrates that we are, indeed, "part of the world of animals". The analysis also indicates other processes with evolutionary "logic" that clarify when the "magic" of these signals expires, or rather which conditions allow the magic of these signals to continue to exist over long periods of time. 
The second type of leadership signals are not seemingly directly related to individual biological instincts, but are acquired developmentally over time. That is, these are signals that can evoke emotions in one group, and not necessarily in another. This is similar to symbols in different areas of life such as a flag, football team, or songs which evoke different emotions in different groups. Leadership is also a symbolic trigger that evokes differential emotional responses.

Prior to the discussion on the impact of such signals, an attempt is made in this chapter to pinpoint the concept of "culture" in the specific context of the discussion on followership. Culture is analyzed here in terms of the typical reactions expressed in regard to preferences and decision-making - aspects that are almost automatic and, as stated, common to a particular group, but not necessarily to another group (e.g., different ethnic groups). This chapter focuses on the aspects relevant to characterizing the cultural signals of leadership.

Chapter 4, "Charisma", "mobilizes" the insights presented in previous chapters regarding "leadership signals" in order to demonstrate and analyze significant cases of charismatic leadership. We use a basic schema we call "neediness and greatness" - a generic schema that describes, for example, the relationship between a baby (a "needy figure") who sends out "distress signals" when he is scared or hungry; and a caregiver (a "large figure") who responds to these distress signals. Different interpretations of this schematic state have been proposed in hundreds of studies conducted in the field of developmental psychology, particularly in attachment studies. ${ }^{52} \mathrm{~A}$ review of leadership studies also indicates the existence of this type of schema in reference to leaders. Such an initial schema is especially evident in crisis situations. In such cases, the effect of primary universal signals is clearly seen in followers-leader dynamics.

However, this is not the whole picture. Humans acquire and carry with them down the road sensitivity to cultural cues. This sensitivity is essential to the "consumption" of leadership and charisma. This argument is exemplified by some known historical cases that serve as a "magnifying glass" that clearly shows the variables and processes discussed. Among the studies and examples discussed in the chapter, the discussion on Hitler was somewhat expanded. This is because: (a) this is an example of a prominent charismatic leader; (b) the circumstances of its occurrence provide an abundance of empirical data which is hard to find for other charismatic leaders; and (c) despite the above, the interpretation of Hitler's charisma is complex and multidisciplinary, and presents conflicting arguments. Using the complex example of Hitler enables the 
presentation of a more comprehensive look at the principles underlying the phenomenon of charisma.

Chapter 5 discusses key issues that the book's arguments did not cover or which may imply assumptions that need to be considered. Observing followership as one of the cornerstones for understanding the phenomenon of leadership, and analyzing the psychological and evolutionary processes underlying followers' need for leaders naturally raise the following questions: If the evolutionary default is to be a follower, then who are the leaders? And why do some individuals emerge from this "automatic pattern" as leaders, while others do not? This is the first issue discussed in the chapter.

The second issue expands the discussion in a context that is much more complex than the paradigm common to "regular" adaptive processes among animals. Human beings have an exceptional ability to learn. This aspect makes the discussion much more complex compared to other mammals' adaptation issues. Consequently, leadership among humans is more complex to analyze compared to any other animal, let's say, leading the herd. Understanding human followership and leadership is related to the combined effect of phylogenetic components (those more universal components that are related to the development of the species as a whole) and symbolic components (acquired and culturally unique). Clarifying this general claim (which may be somewhat obscure at this point) through examples and research is actually at the book's core.

Finally, we provide a recommendation regarding how to read and relate to the contents of the book. We will first present the rationale for this recommendation: some phenomena are simply more "Gestaltic" than others. That is, the whole picture is larger than the sum of its individual parts. For example, seeing a beautiful woman does not necessarily imply that every part of her face is perfect. Sometimes, looking at each part individually detracts from seeing the beauty in its entirety. In our eyes, leadership and certainly charisma are also examples of such phenomena. Up until now, research in this area has always focused on specific variables and in many cases, as noted, on variables that are easier to observe and measure (those variables that are "in the spotlight"). Metaphorically speaking, reading this book may be likened to reading spy novels or detective stories. Each chapter adds information, but the big picture - the "putting together" of all the cumulative pieces of information - only becomes completely clear at the book's end. At least we hope so. 


\section{NOTES}

1. Bruner, Jerome (1986). Actual Minds, Possible Worlds. Cambridge, MA: Harvard University Press.

2. Lindholm, Charles (1988). Lovers and leaders. Social Science Information, March, 27(1) (March), 3-45.

3. Henrich, Joseph, Heine, Steven, and Norenzayan, Ara (2010). The weirdest people in the world? Behavioral and Brain Sciences, 33, 61-135.

4. Segal, Marshal H., Campbell, Donald T., and Herskovits, Melville J. (1966). The Influence of Culture on Visual Perception. Indiana, IN: Bobbs-Merrill.

5. Popper, Micha (2001). Hypnotic Leadership. Westport, CT. Praeger.

6. Bass, Bernard M. (2008). The Bass Handbook of Leadership, 4th edn. New York: Free Press.

7. Popper, Micha (2012). Fact and Fantasy about Leadership. Cheltenham, UK and Northampton, MA, USA: Edward Elgar.

8. Bass, The Bass Handbook of Leadership.

9. Popper, Fact and Fantasy about Leadership.

10. Markus, Hazel and Wurf, Elissa (1987), The dynamic self-concept: A social-psychological perspective. Annual Review of Psychology, 38, 299-337.

11. Liker, Jeffrey and Hoseus, Michael (2008). Toyota Culture: The Heart and Soul of the Toyota Way. New York: McGraw-Hill.

12. Hofstede, Geert (1997). Cultures and Organizations. The Software of the Mind. New York: McGraw-Hill.

13. Burns, James MacGregor (1978), Leadership. New York: Harper \& Row.

14. Shapira, Anita (1997). Yehudim Hadshim, Yehudim Yeshanim. Tel Aviv: Ofakim, Am Oved (Hebrew).

15. Bruner, Actual Minds, Possible Worlds.

16. Kershaw, Ian (1998). Hitler, 1889-1936: Hubris. London: Penguin Books.

17. Ibid., p. xiii.

18. Ibid., p. xiii.

19. Ibid., p. 169.

20. Ibid., p. 170.

21. Shamir, Boas (2007), From passive recipients to active co-producers: Followers' role in the leadership process. In B. Shamir, R. Pillai, M.C. Bligh, and M. Uhl-Bien (eds), Follower-Centered Perspectives on Leadership. Greenwich, CT: Information Publishing, pp. ix-xxxix.

22. Ross, Lee D., Amebile, Teresa M., and Steinmatz, Julia L. (1977). Social roles, social controls and biases in social perception processes. Journal of Personality and Social Psychology, 35, 485-94.

23. Meindl, James R., Ehrlich, Sanford B., and Dukerich, Janet M. (1985). The romance of leadership. Administrative Science Quarterly, 30, 78-102.

24. Liberman, Nira, Trope, Yaakov, and Stephan, Elena (2007). Psychological distance. In A.W. Kruglanski and E.T. Higgins (eds), Social Psychology: Handbook of Basic Principles. New York: Guilford Press, pp. 353-84.

25. Ibid. 
26. Shamir, Boas (1995). Social distance and charisma. Theoretical notes and explanatory study. Leadership Quarterly, 1, 19-48.

27. Meindl, James, R. (1995). 'The romance of leadership as follower-centric theory: A social constructivist approach', Leadership Quarterly, 6, 329-41.

28. Schwartz, Barry (2000). Abraham Lincoln. Forge of National Memory. Chicago, IL: University of Chicago Press.

29. Kets de Vries, Manfred (1988). Prisoners of leadership. Human Relations, 41(31), 261-80.

30. Popper, Fact and Fantasy about Leadership.

31. Skinner, Fredrick (1965). Science and Human Behavior. New York: Free Press. Lewin, Kurt (1947). Frontiers in group dynamics: Concept, method, and reality in social science. Human Relations, 1, 5-42.

32. Halperin, Eran (2014). Emotion, emotion regulation, and conflict resolution. Emotion Review, 6(1), 68-76.

33. Zajonc, Robert B. (1980). Feelings and thinking, preferences need no inferences. American Psychologist, 35(2), 15-175.

34. Kahneman, Daniel (2017). Thinking Fast and Slow. New York: Farrar, Straus \& Giroux.

35. LoBue, Vanessa and DeLoach, Judy S. (2008). Detecting snake in the grass: Attention to fear-relevant stimuli by adults and young children. Psychological Science, 19(3), 284-9.

36. Boyd, Robert and Richerson, Peter (1988). Culture and Evolutionary Process. Chicago, IL: University of Chicago Press.

37. Antonakis, John, Bastardoz, Nicolas, Jacquart, Philippe, and Shamir, Boas (2016). Charisma: An ill-defined and ill-measured gift. Annual Review of Organizational Psychology and Organizational Behavior, 3, 293-319.

38. Howard, Jonathan (1982). Darwin. Oxford: Oxford University Press.

39. Tallhelm, T., Zhang, X., Oishi, S., Shimin, C., Duan, D., Lan, X., and Kitayama, S. (2014). Large-scale psychological differences within China explained by rice versus wheat agriculture. Science, 344(6184), 603-8.

40. Panksepp, Jaak (1998). Affective Neuroscience: The Foundations of Human and Animal Emotions. Oxford: Oxford University Press.

41. Weber, Max (1924/1947). The Theory of Social and Economic Organization, reprinted 1947, trans. Talcott Parsons. New York: Free Press.

42. Vamik, Volkan (2016). Siblings. Charlottesville, VA: Pitchstone Publishing.

43. Boyd and Richerson, Culture and Evolutionary Process.

44. Csibra, Gergely and Gergely, Gyorgy (2009). Natural pedagogy. Trends in Cognitive Sciences, 13, 148-53.

45. Castelnovo, Omri, Popper, Micha, and Koren, Danny (2017). The innate code of charisma. Leadership Quarterly, 28, 543-54. Popper, Micha and Castelnovo, Omri (2018). The function of great leaders in human culture: A cultural- evolutionary perspective. Leadership, 14, 6, 757-74.

46. Van Vugt, Mark, Hogan, Robert, and Kaiser, Robert B. (2008). Leadership, followership, and evolution. American Psychologist, 63(3), 182-96. Van Vugt. M. and Grabo, Allen E. (2015). The many faces of leadership: An evolutionary-psychology approach. Current Directions in Psychological Science, 24(6), 484-9. 
47. Mintzberg, Henry (1973). The Nature of Managerial Work. New York: Harper \& Row.

48. Drath, Wilfred H., McCauley, Cintya D., Palus, J. et al. (2008). Direction, alignment, commitment: Toward a more integrative ontology of leadership. Leadership Quarterly, 19, 635-53.

49. Hofstede, Cultures and Organizations.

50. Gerstner, Charlotte and Day, David (1994). Cross cultural comparisons of leadership prototypes. Leadership Quarterly, 5, 121-34.

51. An interview with Dr. Hai Eithan Inrojack, Haaretz Supplement, November, 30, 2018 (Hebrew).

52. Bowlby, John (1973). Attachment and Loss, Vol. 2: Separation. New York: Basic Books. 